ORIGINAL PROF-2058

\title{
GESTATIONAL DIABETES;
}

Accuracy of glucose challenge test (GCT) for screening.

\section{Dr. Shazia Shaheen, Dr. Robina Ali, Dr. Uzma Afzal}

ABSTRACT... Objective: To determine the Accuracy of GCT for screening of gestational diabetes in high risk population comparing oral Glucose Tolerance Test (GTT) as gold standard. Main outcome measures: Accuracy of GCT. Study design: Cross-sectional study. Setting: The study was conducted in outpatient department of Punjab Medical College and affiliated hospitals, Faisalabad. Subjects: 207 patients. Methods: High risk women from outpatient department were recruited on the basis of inclusion and exclusion criteria after explaining pros and cons of procedure. These women were subjected to GCT \& GTT. GTT was taken as gold standard test and results of GCT were compared with it. Main outcome measures recorded and results obtained. Results: Out of 207 women, GCT truly diagnosed 24 women as having diabetes (true positive) \& 175 women were found to have normal glucose metabolism (true negative). GCT failed to diagnose 5 diabetic women (false negative) \& wrongly diagnosed 3 normal women as diabetics (false positive) against gold standard GTT. So GCT has diagnosed Gestational diabetes mellitus with the sensitivity of $82.7 \%$, specificity of $98.3 \%$, positive predictive value of $88.8 \%$, and negative predictive value of $97.2 \%$ and accuracy of $96.1 \%$. Conclusions: GCT is a simple, easy, convenient and sensitive test that has no limitation for time or prior fasting for gestational diabetes screening.

Key words: Gestational Diabetes Mellitus (GDM), Glucose Challange Test (GCT), GTT.

\section{Article Citation}

Shaheen S, Ali R, Afzal U. Gestational diabetes; Accuracy of glucose challenge test (GCT) for screening. Professional Med J 2013;20(2): 232-236.

\section{INTRODUCTION}

Gestational Diabetes is defined as any degree of glucose intolerance with onset or first recognition during pregnancy ${ }^{1}$. The prevalence of gestational diabetes is proportionate directly to the prevalence of type 2 diabetes mellitus and ethnic background ${ }^{2}$. Approximately $7 \%$ of all pregnancies are complicated by gestational diabetes with the prevalence range of 1 $14^{3}$.

As the incidence of diabetes is rising, so, WHO has predicted that between 1995-2025, there will be a 35\% increase in the worldwide prevalence of diabetes and an additional 1-6\% of women will develop gestational diabetes. The true Prevalence of glucose intolerance during pregnancy in Pakistan is still to be determined but small hospital based studies have given the figures of $3.2 \%$ for GDM and $1.9 \%$ for Impaired glucose tolerance ${ }^{3,9,13}$.

It has been worldwide acknowledged that gestational diabetes is associated with adverse pregnancy outcomes both for the mother and the fetus. The predominant acute effects, however, occur to fetus not to mother. For the Mother in GDM there is higher risk of hypertension, pre-eclampsia, urinary tract infection and caesarean section. It also increases the risk of preterm delivery (three fold) and later type 2 diabetes(70\% $)^{4,5,6}$. In Fetal complications include, congenital anomalies, macrosomia, prematurity, shoulder dystocia and perinatal/Neonatal death. Recurrence rate of GDM is reported $30-70 \%$, 4,6 .

GCT is considered best for screening of gestational diabetes due to its simplicity, acceptability, sensitivity $(50-82 \%)$ and specificity $(64-84 \%)^{6}$.

Normal value of glucose tolerance test:

- $\quad$ True positive: positive by both GCT \& GTT.

- $\quad$ False positive: positive by GCT and negative by GTT.

- $\quad$ False negative: negative by GCT, positive by GTT.

- $\quad$ True negative: negative by GCT \& GTT 
- Accuracy: $=$ Number of true positive + Number of true negative

Number of true positive + false positive + false negative + true negative

\begin{tabular}{|l|c|c|c|}
\hline \multicolumn{1}{|c|}{ Test } & $\begin{array}{c}\text { Normal } \\
\text { Value }\end{array}$ & Impaired & Diabetes \\
\hline $\begin{array}{l}\text { Fasting blood } \\
\text { sugar level }\end{array}$ & $<110 \mathrm{mg} / \mathrm{dl}$ & $\begin{array}{c}110 \_126 \\
\mathrm{mg} / \mathrm{dl}\end{array}$ & $>126 \mathrm{mg} / \mathrm{dl}$ \\
\hline $\begin{array}{l}2 \mathrm{hrs} 75 \mathrm{~g} \\
\text { glucose load, } \\
\text { blood sugar }\end{array}$ & $<140 \mathrm{mg} / \mathrm{dl}$ & $\begin{array}{c}<140 \_200 \\
\mathrm{mg} / \mathrm{dl}\end{array}$ & $>200 \mathrm{mg} / \mathrm{dl}$ \\
\hline
\end{tabular}

Table-I.

\section{MATERIAL AND METHOD}

It was comparative cross sectional study conducted in DQH Hospital, affiliated with Punjab Medical College, Faisalabad. 207 high risk women were included in the study. It was a non-probability consecutive sampling. After fulfilling the inclusion criteria like: Pregnant females having any of these were considered high risk population and were included in the study, BMI more than $25 \mathrm{~kg} / \mathrm{m}^{2}$, Family history of diabetes (first degree relatives), Previous history of Gestational diabetes, Macrosomia, Shoulder dystocia, Polyhydramnios, Miscarriage, Intrauterine death \& in current pregnancy polyhydramnios or congenital anomalies \& excluding all women with pre-gestational diabetes.

Every patient was given $50 \mathrm{~g}$ glucose in $200 \mathrm{ml}$ of water and patient was asked to drink. After one hour venous blood sample was taken to check blood sugar level. Results were noted. Irrespective of results every patient was recalled on next morning with fasting of eight hours. First venous blood sample was drawn immediately to check fasting blood sugar level. Then every patient was be given $75 \mathrm{~g}$ glucose in $250 \mathrm{ml}$ of water to drink. After 2 hours another blood sample was drawn and checked for blood sugar level, sugar levels were checked.

GCT was considered positive if one hour post blood glucose level was more than $140 \mathrm{mg} / \mathrm{dl}$. Glucose tolerance test was considered positive if fasting sugar level was more than $126 \mathrm{mg} / \mathrm{dl}$ and two hours post blood glucose level was more than $200 \mathrm{mg} / \mathrm{dl}$.

\section{DATAANALYSIS}

SPSS version 10 was used for data analysis. Mean and standard deviation were determined for age, body mass index and parity. Frequency and percentages were calculated for results of risk factors, GCT, GTT and then accuracy of test was determined using GTT as gold standard test.

\section{RESULTS}

During the 06 month study period GCT was performed on a total of 207 patients. Baseline characteristics of blood sugar level are shown in Table I. Mean age of these women was $26.9 \pm 5$.4. Mean of parity was 2.8 \pm 2 . Mean of BMI was $26.3 \pm 4$. Out of 207 women, GCT truly diagnosed 24 as having diabetes (true positive) \& 175 women were found to have normal glucose metabolism (true negative).GCT failed to diagnose 5 diabetic women (false negative) \& wrongly diagnosed 3 normal persons as diabetics (false positive).

Regarding relation of diabetes with different age groups, frequency of GDM was found to be increased with increasing age groups as $34.5 \%(10)$ women were in age group <25years, $58.6 \%$ (17) in age group 25 -34years and $6.9 \%$ (2) in age group 35 or $>$ years.

GDM was also more prevalent in multipara $(69 \%, 20 / 29)$ in contrast with primigravida or nullipara( $31 \%, 9 / 29$ ). Most of Diabetic women were having BMI between $25-29(48.3 \%, 14 / 29)$ followed by BMI $<25$ $(37.9 \%, 11 / 29)$ and at last was BMI 30 or $>(13.8 \%$, $4 / 29)$.

In study subjects out of 29 diabetic women $62 \%$ had 2 risk factors vs $39.8 \%$ in non-diabetics, $24 \%$ had 3 risk factors vs $39.8 \%$ in non diabetics, $10.3 \%$ with 1 risk 
factor Vs 43.2\%. 3.4\% diabetics were having 4 risk factors.

Out of 29 diabetic women 16 were above 25 years, 15 with $\mathrm{BMI}>25,5$ with past history of miscarriage, 6 were having history of unexplained IUD, 5 with congenital malformations, 2 with polyhydramnios, 3 with past history of shoulder dystocia, 2 with past macrosomia, 2 with past history of GDM and 10 women were having family history of Diabetes Mellitus Frequency of different risk factors in diabetes.(TableII).

\begin{tabular}{|l|c|c|c|c|}
\hline \multicolumn{1}{|c|}{ Variable } & \multicolumn{2}{c|}{ Diabetic } & \multicolumn{2}{c|}{ Non-diabetic } \\
\hline & Frequency & \%age & Freq. & \%age \\
\hline DM & 10 & 34.5 & 21 & 11.8 \\
\hline $\begin{array}{l}\text { Congenital } \\
\text { anomalies }\end{array}$ & 5 & 17.2 & 9 & 5 \\
\hline GDM & 2 & 6.9 & 6 & 3.4 \\
\hline $\begin{array}{l}\text { Shoulder } \\
\text { dystocia }\end{array}$ & 1 & 10.3 & 8 & 4.5 \\
\hline Macrosomia & 2 & 6.9 & 6 & 5.1 \\
\hline Miscarriage & 5 & 17.2 & 24 & 13.5 \\
\hline IUD & 6 & 20.7 & 26 & 14.6 \\
\hline Polyhtdramnios & 2 & 6.9 & 11 & 6.2 \\
\hline Age>25 & 16 & 55.2 & 94 & 52.8 \\
\hline BMl>25 & 15 & 51.7 & 95 & 53.4 \\
\hline
\end{tabular}

Table-Il. Frequency of different risk factors

\begin{tabular}{|c|c|c|c|}
\hline $\begin{array}{c}\text { Test } \\
\text { positive }\end{array}$ & $\begin{array}{c}\text { True positive } \\
\text { (TP) } 24\end{array}$ & $\begin{array}{c}\text { False positive } \\
\text { (FP) } 3\end{array}$ & Total 29 \\
\hline $\begin{array}{c}\text { Test } \\
\text { negative }\end{array}$ & $\begin{array}{c}\text { False negative } \\
\text { (FN) } 5\end{array}$ & $\begin{array}{c}\text { True negative } \\
\text { (TN) } 175\end{array}$ & Total 178 \\
\hline
\end{tabular}

\section{Table-III. GCT results}

According to this study GCT has diagnosed Gestational diabetes mellitus with the sensitivity
$82.7 \%$, specificity $98.3 \%$, positive predictive value $88.8 \%$, and negative predictive value $97.2 \%$ and accuracy $96.1 \%$. (Table-IV).

\begin{tabular}{|l|c|c|}
\hline Sensitivity (\%) & TP X 100 / (TP + FN) & $82.7 \%$ \\
\hline Specificity (\%) & TP X 100 / (TN + FP) & $98.3 \%$ \\
\hline $\begin{array}{l}\text { Positive predictive } \\
\text { value (\%) }\end{array}$ & TP X 100 / (TP + FP) & $88.8 \%$ \\
\hline $\begin{array}{l}\text { Negative predictive } \\
\text { value (\%) }\end{array}$ & TP X 100 / (FN + TN) & $97.2 \%$ \\
\hline Accuracy (\%) & TP + TN X 100 / 207 & $96.1 \%$ \\
\hline
\end{tabular}

Table-IV. GCT test characteristics / accuracy

\section{DISCUSSION}

GDM has been recognized for decades and it has also been acknowledged that screening of GDM holds clinical validity on the basis of improved obstetric outcomes but still it is on the horns of dilemma. Internationally there remains no agreement on whom (Universally or target population), when and how to screen for gestational diabetes ${ }^{1}$. In developing countries like Pakistan Systematic screening of gravid women is still not common and selective screening of high risk population has an acceptable performance and is preferred due to poor resources, lack of health facilities at home ground, lack of awareness among health professionals and cost factors. In addition to these, an important reason for this is that a large percentage of women deliver at home with the help of traditional birth attendants and thus increasing the prevalence of high risk population ${ }^{9,13}$.

A careful review of literature has shown that studies evaluating GCT as a screening test for GDM in Pakistan are very scarce. As indicated by several studies that this test may have population specific effects, it was therefore desirable to carry out a systematic study in larger population. The present work presents data in respects of 207 subjects coming from peripheries around the 3rd biggest city of Pakistan. Whichever selection criteria is used it is essential to rely on valid 
diagnostic test. Therefore, limiting formal screening in women with risk factors is an acceptable option in setting lacking in resources.

A variety of risk factors and different combinations of risk factors have been so far determined to label the patient as "high risk for development of GDM". These are different in different populations. In this study $62 \%$ $(18 / 29)$ had two, 24\% (7/29) had three, 10.3\%(3/29) one and $3.4 \%(1 / 29)$ had four or more risk factors. It was observed that increase in the number of risk factors increases the risk of development of GDM as none of the women with four or more risk factors was having normal glucose tolerance. The same result was given by Jaroslaw Ogonowski's study "predictive value of traditional risk factors in identifying women at risk of $\mathrm{GDM}^{2}$.

One of the risk factor in this study was maternal age that showed age > 25 years present in 110 (55.2\%) population subjects but it was almost equal distributed in both diabetic women (55.2\%) and non-diabetics (52.8\%). The same result was given by Chanprapaph $P$ that states commonest indication for GCT was advanced maternal age $(75.4 \%)^{3}$.

Next important risk factor Genetic predisposition with diabetes in first degree relatives with prevalence of $34.5 \%(10 / 29)$ in diabetics and $11.8 \%(21 / 178)$ in non-diabetics. So family history of diabetes was 2-3 fold more common in diabetics in comparison with non-diabetics. My results were comparable to another study $(39.6 \%)$ in diabetics and $18.6 \%$ in nondiabetics) in positive family history ${ }^{4}$. The past history of GDM was present in 2/29 (6.9\%) of women with GDM as compared to 6/178(3.4\%) of non diabetics. This is in comparison with Jaroslaw Ognowski (OR $4.3595 \% \mathrm{Cl}:$ : 2.42-7.82) with prior $\mathrm{GDM}^{2}$.

Other risk factors were previous history of unexplained IUD, shoulder dystocia, and macrosomia, maternal
$\mathrm{BMI}>30 \mathrm{~kg} / \mathrm{m}^{2}$ were significantly increase the risk of GDM in this study. As compared to Senanayake $\mathrm{H}$ defined 1 st degree relatives, maternal age $>35$ years, unexplained stillbirth and fetal malformations are important risk factors for development of $\mathrm{GDM}^{5}$. After two step diagnostic protocol was adopted in this study and GCT was chosen as initial screening test. GCT has diagnosed Gestational diabetes mellitus with the sensitivity $84.6 \%$, specificity $98 \%$, positive predictive value $88 \%$, negative predictive value $27.8 \%$ and accuracy $96.6 \%$.

These statistical values change with change in the threshold of plasma glucose concentration for diagnosis. Two threshold values used for GCT in literature are $130 \mathrm{mg} / \mathrm{dl}$ and $140 \mathrm{mg} / \mathrm{dl}$. This predefined threshold of $140 \mathrm{mg} / \mathrm{dl}$ was used in my study.

The $\geq 140 \mathrm{mg} / \mathrm{dl}$ plasma glucose threshold has sensitivity of $80 \%$ and specificity of $90 \%$ for GDM. $10 \%$ of GDM women have plasma glucose concentration between $130-140 \mathrm{mg} / \mathrm{dl}$ so lowering the threshold $\geq$ $130 \mathrm{mg} / \mathrm{dl}$ increases the sensitivity to $90 \%$ but also increases the number of women requiring diagnostic testing by $60 \%$. The ADA supports both values. Ardawi MS et al in their study conducted at King AbdulAziz University Hospital Saudi Arabia found maximum sensitivity and specificity of GCT at plasma glucose value of $140 \mathrm{mmol} / \mathrm{L}$ to be $88 \%$ and $84 \%$ with a positive predictive value of $82 \%{ }^{12}$. The global controversy over the screening criteria for gestational diabetes has been reflected in Pakistan. The weakness of my study was that it was performed in a small hospital setting, which was not representative of majority of Pakistani population. This uncertainty mandates serious and local research dedicated towards achieving valid figures.

\section{CONCLUSIONS}

Little has changed over the last 50 yrs but in developing countries like Pakistan "selective screening of high risk population with Glucose 
challenge test", as simple, easy, convenient and sensitive test that has no limitation for time or prior fasting, has an acceptable performance and is preferred due to poor resources, lack of health facilities at home ground, lack of awareness among health professionals and, cost factors.

\section{Copyright@ 01 Jan, 2013.}

\section{REFERENCES}

1. Dornhost A, Williamson C. Diabetes and endocrine disease in pregnancy. In: Edmons DK, editor. Dewhurst's textbook of obstetrics and gynaecology. 7th ed. Oxford: Blackwell; 2007:246-59.

2. Key TC, Giuffrida R, Moore TR. Predictive value of early pregnancy glycohemoglobin in the insulin treated diabetic patient. Am J Obstet Gynecol. 1987;156:273-80.

3. Magee MS, Walden CE, Benedetti TJ, Knopp RH. Influence of diagnostic criteria on the incidence of gestational diabetes and perinatal mortality. JAMA. 1993;269:609-15.

4. Hadaegh F, Tohidi M, Harati H, Kheirandish M, Rahimi S. Prevalence of gestational diabetes mellitus in southern Iran (Bandar Abbas City). Endocrine Practice. 2005;11:313-8.

5. Soheilykhah S, Moghibian M, Rahimi-Saghand S, Rashidi M, Soheilykhah S, Piroz M. Incidence of gestational diabetes mellitus in pregnant women. Iranian J Reprod Med. 2010;8:24-8.

6. Carpenter MW, Coustand. Criteria for screening test

AUTHOR(S):

1. DR. SHAZIA SHAHEEN

MBBS, FCPS

Senior Registrar

Gynae \& Obst Unit-II

DHQ Hospital, Faisalabad

2. DR. ROBINA ALI

MBBS, FCPS, MCPS

Associate Professor

Gynae \& Obst Unit-II

DHQ Hospital, Faisalabad. for gestational diabetes. Am J Obstet Gynecol. 1982;144:768-73.

7. Rey E, Hudon L, Michon N, Bochar T, Ethier J, SaintLouis $P$. Fasting plasma glucose versus glucose challenge test: screening for gestational diabetes and cost effectiveness. Clin Biochem. 2004;37:780-4.

8. Dabelea D, Snell-Bergeon JK, Hartsfield CL, Bichoff KJ HammanRF, McDuffie RS. Increasing prevelanew of gestational diabetes Mellitus over time and by birth cohort: Kaiser permanente of Colorado GDM Screening Program. Diabetes Care. 2005;28:579-84.

9. Naheed F, Kammeruddin K, Hashmi HA, Narijo S. Frequency of impaired oral glucose tolerance test in high risk pregnancies for gestational diabetes mellitus. J Coll Physicians Surg Pak. 2008;18:82-5.

10. Abolfazl M, Hamidreza TS, Narges M, Maryam Y. Gestational diabetes and its association with unpleasant outcomes of pregnancy. Pak J Med Sci. 2008;24:566-70.

11. Wender-Ozegowska E, Wroblewska K, Zawiejska A, Pietryga M, Szezapa J, Biczysko R. Threshold values of maternal blood glucose in early diabetic pregnancyprediction of fetal malformations. Acta Obstet Gynecol Scand. 2005;84:17-25.

12. Ardawi MS, Nasrat HA, Jamal HS, Al-Sagaff HM, Mustafa BE. Screening of Gestational Diabetes Mellitus in pregnantfemale. Saudi Med J. 2000;21:155-60.

13. Samad NJ, Hassan JA, Shera AS, Maqsood A. Gestational diabetes mellitus-screening in a developing country. J Pak Med Assoc. 1996;46: 249-52. 